\title{
Potent potassium
}

Lars Öhrström ponders the importance of potassium in matters of life and death.

1 $\mathrm{s}$ an essential element (we need to consume 1-5 grams per day), potassium is life-preserving, but it is also intimately associated with danger and even death. The electrochemical experiments through which Davy isolated the element in 1807 electrolysis of molten caustic potash $(\mathrm{KOH})$ - were not for the faint-hearted, and a year later young Gay-Lussac got first-hand evidence of the reactivity of the pure metal in $\sum_{i}$ an explosion that left him with damaged eyesight for life ${ }^{1}$.

The most sinister use of potassium is as chloride solutions injected into the bloodstream. Such intravenous injections are potentially lethal and serve for executions in some US states, although they are also used to treat potassium deficiency. $\mathrm{KCl}($ aq.) has been implicated in tragic medical errors, as well as gruesome serial killings, because it is difficult to detect and the cause of death often seems deludingly natural ${ }^{2}$. A rapid analysis is required to identify potassium poisoning - anecdotally, this makes using it in crime novels awkward, as the prompt analysis would force writers to divulge the plot too early ${ }^{3}$.

In our bodies there is a fine balance between the $\mathrm{K}^{+}$and $\mathrm{Na}^{+}$concentrations inside and outside the cells, and it is the disruption of this balance that makes $\mathrm{KCl}$ injections lethal. Potassium ions are transported across the biological membranes through proteins known as potassium channels (pictured). Studies on these ion channels afforded Roderick MacKinnon the 2003 Nobel Prize in Chemistry, but the detailed mechanism at play is still under debate; the predominant idea of water cotransport was recently challenged by the

\section{suggestion of a direct $\mathrm{K}^{+}-\mathrm{K}^{+}$'Coulomb}

knock-on' mechanism ${ }^{4}$.

Element 19 comes with two aliases: variations of 'potassium' are common in many languages and it is also known as kalium, from which its symbol $\mathrm{K}$ is derived. The previous paragraphs could lead one to believe that it derives from the Hindu goddess Kali, whose name is associated with death, but just as 'potassium' it comes from one of the early compounds, $\mathrm{K}_{2} \mathrm{CO}_{3}$ known as potash or al-qalyah in Arabic, which is of course 'al-kaline's.

Some chemists may consider element 19 dull, as it often is merely a counter-ion without specific function. This is far from the case however. Saltpetre $\left(\mathrm{KNO}_{3}\right)$ for example, once the most important potassium compound, was a superior oxidant in gunpowder for ancient firearms compared with its more hygroscopic analogue $\mathrm{NaNO}_{3}$.

The source of potassium ions had traditionally been potash, historically an important export from northern Europe, obtained by the extraction of wood ashes and subsequent crystallization in pots. Today potassium is mined primarily as $\mathrm{KCl}$ in North America and Russia. Its main use is as a macronutrient in 'NPK' fertilizers, along with nitrogen and phosphorus as the name implies. Operations are on a huge scale, as the uptake in crops is large and demands that potassium constantly be replaced in the soil, yet we do not risk depleting resources as it is the eighth most abundant element in the Earth's crust ${ }^{6}$.

The chemistry of potassium is dominated by the $\mathrm{K}^{+}$cation and its mainly electrostatic interactions. Significant coordination chemistry also arises from the introduction of crown-ethers and related compounds ${ }^{5}$. Some of these hosts have helped shed light on the biological role of potassium; others have been used to promote disproportionation into complex-bound $\mathrm{K}^{+}$ and $\mathrm{K}^{-}$counter ions, demonstrating a small but significant electron affinity of this very electropositive element.

The crown-ether complexes of the alkali metals also nicely illustrate the trend in sizes within this group. The reactivity trends are also very regular; reacting sodium with water is a classic demonstration, but the larger size and lower ionization energy of potassium make the corresponding experiment dangerous as the generated hydrogen gas will invariably ignite and explode. Thus, although organic solvents are typically dried by distillation over pieces of $\mathrm{Na}$, the use of potassium metal as a substitute is not advisable. Yet this is exactly what chemistry student Primo Levi did when given the task of distilling benzene, and could not find sodium metal in Turin's war-depleted stock rooms. Although he handled his piece of potassium "like a holy relic" the lab still caught fire, but luckily for himself - and literature - he was able to extinguish the blaze ${ }^{7}$.

Whether in biological systems or laboratory settings, rather than a mere spectator counter-ion potassium often assumes a role that is a matter of life and death.

\section{LARS ÖHRSTRÖM author of The Last} Alchemist in Paris \& Other Curious Tales From Chemistry is in the Department of Chemistry and Chemical Engineering, Chalmers University of Technology, SE-412 96 Gothenburg, Sweden. e-mail: ohrstrom@chalmers.se; Twitter:@Larsohrstrom

\section{References}

1. Michalovic, M. Not-so-great moments in chemical safety. Chemical Heritage Magazine 26 (2008); http://go.nature.com/MxhAtw

2. Emsley, J. Molecules of Murder: Criminal Molecules and Classic Cases (Royal Society of Chemistry, 2008).

3. Matsson, O. En dos Stryknin: om Gifter och Giftmord i Litteraturen (Atlantis, 2012).

4. Köpfer, D. A. et al. Science, 346, 352-355 (2014).

5. Greenwood, N. N. \& Earnshaw, A. Chemistry of the Elements (Pergamon Press, 1997).

6. Freilich, M. B. \& Petersen, R. L. in Kirk-Othmer Encyclopedia of Chemical Technology http://doi.org/25z (John Wiley \& Sons, 2014). 7. Levi, P. The Periodic Table (Abakus, 1985).
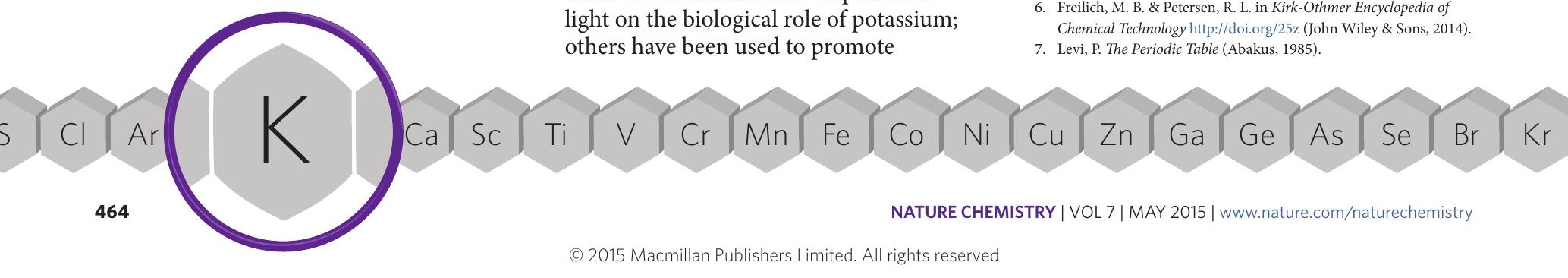